\title{
O ENFERMEIRO NOS EVENTOS ADVERSOS A MEDICAÇÃO NA PEDIATRIA.
}

\section{Pôster}

Autores deste trabalho:

Ricardo Alexandre Spironello: Universidade Estadual de Maringá (UEM)

Roberto Kenji Nakamura Cuman: Universidade Estadual de Maringá (UEM)

Área do Trabalho: Enfermagem pediátrica

Data da submissão:21/06/2018 às 16:08

\section{Justificativa}

A sepse é uma das principais causas de mortalidade e morbidade em pediatria e neonatologia. Além de um diagnóstico rápido, o início imediato do tratamento com antibioticoterapia empírica, é uma emergência em infecções neonatais e pediátricas. $\mathrm{O}$ uso prolongado pode promover reações adversas e resistência aos antimicrobianos

\section{Objetivo(s)}

Relatar um caso clinico de sepse neonatal, o conhecimento teórico- pratico no processo de enfermagem, visando uma maior qualidade da assistência prestada a um recém- nascido e pacientes pediátricos, no manejo terapêutico relacionado a multiantibiótico terapia em uma Unidade de Tratamento Intensivo Neonatal (UTIN) em um hospital em Maringá.

\section{Método(s)}

Relato Clínico: Um RN pré-termo nascido por cesárea de 34 semanas e dois dias de gestação, apresentando restrição de crescimento intrauterino.

\section{Resultado(s)}

Após diagnóstico de insuficiência respiratória, o recém nascido foi intubado, submetido à ventilação mecânica e encaminhado à UTIN. Segundo protocolo, ampicilina e gentamicina foram instituídos empiricamente. Foi diagnosticado sepse por Enterobacter spp. Pelo agravo do quadro clínico, a antibioticoterapia foi alterada, sendo administrados: oxaciclina, amicacina, cefepime, tazocin, meropeno e teicoplamina, conforme a resposta clínica do paciente. Administrar antibióticos sem precisar, pode aumentar a quantidade de germes multirresistentes e piorar o RN. Após sessenta dias internado na UTIN, os parâmetros clínicos e laboratoriais foram normalizados e houve alta hospitalar do neonato.

\section{Conclusão (ões)}

Muitos recém-nascidos e pacientes pediátricos não estão desenvolvendo a sepse e sim manifestações clinicas inespecíficas, e isso pode confundir a conduta do enfermeiro. O Enfermeiro desenvolve um cuidado altamente complexo e especializado a um paciente na neonatal e pediatrico, sendo necessário o conhecimento de todos os parâmetros específicos na assistência. $O$ trabalho da equipe da enfermagem é imprescindível para identificar as alterações clinicas destes pacientes, essa vigilância nos cuidados pode diagnosticar manifestações precoces da 


\section{$4^{\circ}$ Congresso Internacional Sabará \\ 13 a 15 de \\ 13 a 15 de 2018}

Hotel Maksoud Plaza
Alameda Campinas, 150
Säo Paulo- Brosil

sepese entre outras doenças. O tratamento empírico e prolongado com antibióticos, de amplo espectro, deve ser cuidadosamente avaliado em pacientes pediátricos. Após a analise deste caso houve treinamento da equipe de enfermagem para deteç̧ão precoce da sepse e conhecimentos de antibioticoterapia. Envolvendo um melhor diagnostico, eficácia de drogas, reações adversas a medicamentos. 